\title{
Desenvolvimento de massas de revestimento cerâmico com argila caulinítica e nefelina sienito
}

\author{
(Development of ceramic tile bodies with kaolinitic \\ clay and nepheline-syenite)
}

\author{
C. M. F. Vieira, J. B. Soares, S. N. Monteiro \\ Laboratório de Materiais Avançados - LAMAV, Universidade Estadual do Norte Fluminense Darcy Ribeiro \\ Av. Alberto Lamego 2000, Campos dos Goytacazes, RJ 28013-602 \\ vieira@uenf.br
}

\begin{abstract}
Resumo
Este trabalho tem por objetivo adicionar tanto o fundente nefelina sienito, disponível no Estado do Rio de Janeiro, quanto o talco, fornecido por uma mineradora, em uma argila caulinítica para a obtenção de revestimento cerâmico gresificado. Foram preparadas formulações com $0 \%, 30 \%$ e $50 \%$ em peso de nefelina sienito em mistura com a argila, com e sem a adição de 3,5\% em peso de talco. O comportamento de queima das formulações foi avaliado por dilatometria óptica. Corpos-de-prova foram obtidos por prensagem uniaxial a $30 \mathrm{MPa}$ para queima a $1175^{\circ} \mathrm{C}$. Nas amostras queimadas foram realizados ensaios tecnológicos para determinação da densidade aparente, retração linear, resistência mecânica por flexão em três pontos e absorção de água. Análise microestrutural foi feita por microscopia eletrônica de varredura e difração de raios X. Os resultados mostraram que a as formulações com nefelina sienito e talco apresentam potencial para a obtenção de revestimento gresificado, reduzindo significativamente a porosidade da cerâmica argilosa pura.
\end{abstract}

Palavras-chave: argila, caulinita, fundente, nefelina sienito, microestrutura, revestimento cerâmico.

\begin{abstract}
This work had for objective to add both the nepheline-syenite flux, available in the State of Rio de Janeiro, and the talc, purchased from a mining company, into a kaolinitic clay to obtain vitrified ceramic tile. Mixtures were prepared with addition of 0,30 and $50 \mathrm{wt} . \%$ of nepheline-syenite to a kaolinitic clay. The talc was added in the amount of 0 and $3.5 \mathrm{wt} . \%$. The firing behavior of the formulations was evaluated by optical dilatometry. Specimens were prepared by uniaxial pressure at $30 \mathrm{MPa}$ followed by firing at $1175{ }^{\circ} \mathrm{C}$. The fired specimens were submitted to the following tests: bulk density, linear shrinkage, three point bending mechanical strength and water absorption. Microstructural analysis was carried out by scanning electron microscopy and X-ray diffraction. The results showed that the formulations with both nepheline-syenite and talc addition have a potential to obtain vitrified ceramic, by significantly decreasing the porosity of the pure clayey ceramic.
\end{abstract}

Keywords: clay, kaolinite, flux, nepheline-syenite, microstructure, ceramic tile.

\section{INTRODUÇÃO}

A cidade de Campos dos Goytacazes, localizada ao norte do estado do Rio de Janeiro, apresenta-se como o grande pólo de cerâmica vermelha do Estado do Rio de Janeiro. Dados recentes [1] indicam a existência de mais de 100 indústrias cerâmicas sindicalizadas em Campos, com 6.000 empregos diretos, gerando cerca de $\mathrm{R} \$ 168$ milhões por ano, decorrente de uma produção estimada em 75 milhões de peças por mês. A matéria-prima utilizada é uma argila de predominância caulinítica, que provém da própria região. A maior parte da produção é voltada para a fabricação de blocos de vedação, um produto de baixo valor agregado.

A implantação de indústrias voltadas para a fabricação de revestimentos prensados de baixo custo, produzidos por via seca utilizando argilas regionais na composição da massa, desponta como uma alternativa para a diversificação de produtos com maior valor agregado e aprimoramento do pólo cerâmico de Campos dos Goytacazes.

Argilas cauliníticas não apresentam características satisfatórias para serem utilizadas como único componente de massa para revestimento cerâmico, devido principalmente ao seu comportamento refratário durante a queima [2, 3]. Alguns trabalhos reportados na literatura mostraram que há necessidade da adição de fundentes às argilas cauliníticas de Campos dos Goytacazes para a obtenção de revestimento para pavimento [4-6]. O fonolito e a argila ilítica da região de Santa Gertrudes, interior do estado de São Paulo, foram as matérias-primas fundentes mais promissoras. Estas, quando adicionadas às argilas de Campos dos Goytacazes possibilitaram uma melhoria significativa nas suas propriedades de queima [4]. Por outro lado, trata-se de matérias-primas não disponíveis no estado do Rio de Janeiro, o que pode inviabilizar sua utilização 
por questões econômicas.

Nefelina sienito é uma rocha ígnea alcalina, sem a presença de quartzo e com predominância de feldspatos (microclínio e albita), feldspatóides (Nefelina sodalita), dolomita, monazita e minerais portadores de ferro (óxido e/ ou sulfetos). Possui coloração variando de incolor à branca amarelada, dureza de 6 na escala Mohs e 2,6 g/ $\mathrm{cm}^{3}$ de peso específico. Tais propriedades são bem semelhantes às do feldspato, fazendo com que a nefelina sienito desponte como matéria-prima fundente de grande potencial, podendo mesmo substituir o feldspato [7].

Lynch e Allen [8] investigaram a utilização da nefelina sienito em mistura com talco como fundente para a produção de cerâmica vitrificada em baixa temperatura. Foi concluído que a mistura com $85 \%$ em peso de nefelina e $15 \%$ em peso de talco reduziu a temperatura de vitrificação. Sabedot et al. [9] caracterizaram e aplicaram processos de tratamento mineral em rocha nefelina sienito para se definir uma rota de beneficiamento viável para utilizá-la como fundente em massa de grês-porcelanato. Os resultados obtidos indicaram que a rota de separação magnética a seco seria a mais indicada para a obtenção de material com teor de óxido de ferro satisfatório para a obtenção de porcelanato.

O talco, também investigado neste trabalho, é considerado um material modificador de fundência [10, 11], pois reage com os feldspatos formando eutéticos. Trabalhos comprovaram a eficiência do talco na redução da temperatura de vitrificação de massas de revestimento cerâmico [12-14]. A adição de talco é geralmente limitada a $10 \%$ em peso, para não prejudicar o coeficiente de expansão térmica da cerâmica e não reduzir demasiadamente a faixa de temperatura de queima $[9,10]$.

Nesse contexto, o presente trabalho teve como objetivo adicionar o fundente nefelina sienito e o talco em argila caulinítica para a obtenção de revestimento cerâmico gresificado.

\section{MATERIAIS E MÉTODOS}

Foram utilizados os seguintes materiais: argila caulinítica, nefelina sienito e talco. A argila, de coloração cinza e de elevada plasticidade, é empregada em composição de massa de cerâmica vermelha pelas indústrias do pólo cerâmico de Campos dos Goytacazes, RJ [15]. A nefelina sienito, com tamanho de partícula inferior a 200 mesh $(0,074 \mathrm{~mm})$, foi adquirida de uma pedreira localizada no município de Nova Iguaçu, estado do Rio de Janeiro. O talco, com granulometria inferior a 200 mesh $(0,074 \mathrm{~mm})$, foi fornecido pela mineradora Armil.

Foram preparadas cinco formulações indicadas na Tabela I. A sigla A representa argila pura, enquanto que $\mathbf{N}$ representa nefelina sienito e $\mathbf{T}$ talco. As quantidades de nefelina sienito e de talco utilizadas estão baseadas em valores normalmente encontrados na literatura para fundentes e modificadores de fundência em composição de massa de cerâmica vitrificada [16].

A argila caulinítica foi triturada em almofariz de
Tabela I - Formulações estudadas (\% em peso).

[Table I - Studied formulations (wt.\%).]

\begin{tabular}{cccc}
\hline & \multicolumn{3}{c}{ Matérias-primas } \\
\cline { 2 - 4 } Formulação & $\begin{array}{c}\text { Argila } \\
\text { caulinítica }\end{array}$ & $\begin{array}{c}\text { Nefelina } \\
\text { sienito }\end{array}$ & Talco \\
\hline A & 100 & - & - \\
A30N & 70 & 30 & - \\
A50N & 50 & 50 & - \\
A30NT & 66,5 & 30 & 3,5 \\
A50NT & 46,5 & 50 & 3,5 \\
\hline
\end{tabular}

porcelana até total passagem em mallha ABNT 80 mesh. Em seguida, as composições elaboradas foram homogeneizadas a seco em moinho de bolas, com revestimento de porcelana, durante $60 \mathrm{~min}$.

Ensaios dilatométricos foram realizados em dilatômetro óptico Misura 3.32, com taxa de aquecimento $10^{\circ} \mathrm{C} / \mathrm{min}$.

Para outros ensaios tecnológicos foram preparados corpos-de-prova retangulares $\left(11,43 \times 2,54 \times 0,8 \mathrm{~cm}^{3}\right)$ por prensagem uniaxial a $30 \mathrm{MPa}$ com $8 \%$ de umidade. Em seguida, os corpos-de-prova foram secos em estufa a $110{ }^{\circ} \mathrm{C}$ por $24 \mathrm{~h}$. A etapa de queima foi realizada em forno de laboratório nas temperatura de $1175{ }^{\circ} \mathrm{C}$, típica de revestimento cerâmico de baixa porosidade [11]. A taxa de aquecimento empregada foi de $10{ }^{\circ} \mathrm{C} / \mathrm{min}$ com $6 \mathrm{~min}$ na temperatura de patamar. $\mathrm{O}$ resfriamento foi realizado desligando-se o forno. Após queima, cinco corpos-de-prova de cada formulação foram submetidos aos seguintes ensaios: densidade aparente a seco e de queima, retração linear, absorção de água e tensão de ruptura por flexão em 3 pontos [17,1 8].

A análise microestrutural foi feita por meio da observação da superfície de fratura das cerâmicas em um microscópio eletrônico de varredura Jeol modelo JSM6460LV, com EDS acoplado, e por difração de raios $\mathrm{X}$ em um difratômetro Seifert, modelo URD 65, com radiação Co- $\mathrm{k}_{\alpha}$.

\section{RESULTADOS E DISCUSSÃO}

A Fig. 1 apresenta o difratograma de raios $\mathrm{X}$ da argila. Observam-se picos de difração correspondentes a caulinita $\left(\mathrm{Al}_{2} \mathrm{O}_{3} \cdot 2 \mathrm{SiO}_{2} \cdot 2 \mathrm{H}_{2} \mathrm{O}\right)$, quartzo $\left(\mathrm{SiO}_{2}\right)$, gibsita $\left(\mathrm{Al}_{2} \mathrm{O}_{3} \cdot 3 \mathrm{H}_{2} \mathrm{O}\right)$ e mica muscovita $\left(\mathrm{K}_{2} \mathrm{O} \cdot 3 \mathrm{Al}_{2} \mathrm{O} 3 \cdot 6 \mathrm{SiO}_{2} \cdot 2 \mathrm{H}_{2} \mathrm{O}\right)$. A caulinita é o argilomineral responsável pelo desenvolvimento de plasticidade e apresenta comportamento de queima refratário. $\mathrm{O}$ quartzo se constitui na principal impureza presente nas argilas, atuando como matéria-prima não plástica e inerte durante a queima. A gibsita contribui para o aumento da refratariedade das argilas e da perda de massa durante a queima. A mica muscovita é um mineral com textura lamelar que pode ocasionar o aparecimento de defeitos nas peças cerâmicas. Desde que apresente tamanho de partícula reduzido, a mica muscovita pode atuar como fundente devido à presença de óxidos alcalinos como $\mathrm{K}_{2} \mathrm{O}$ e $\mathrm{Na}_{2} \mathrm{O}$.

$\mathrm{O}$ difratograma de raios $\mathrm{X}$ da nefelina sienito é apresentado na Fig. 2. A nefelina sienito apresenta picos 


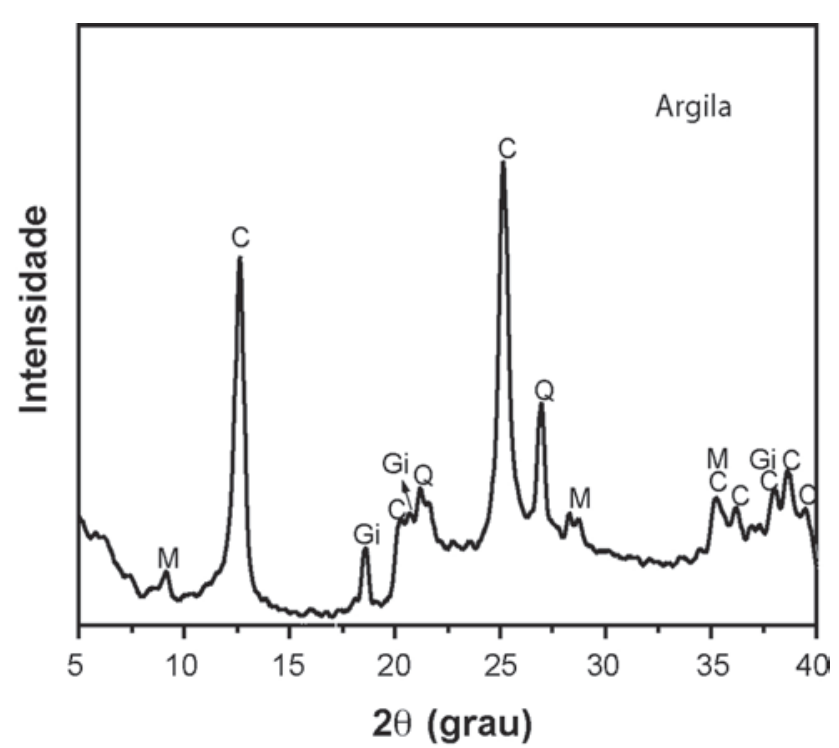

Figura 1: Difratrograma de raios $\mathrm{X}$ da argila. C: caulinita, Gi: gibsita, M: mica muscovita, Q: quartzo.

[Figure 1: X-ray diffraction pattern of the clay. kaolinite $=C$; gibbsite $=G i$; muscovite mica $=M ;$ quartz $=Q$.

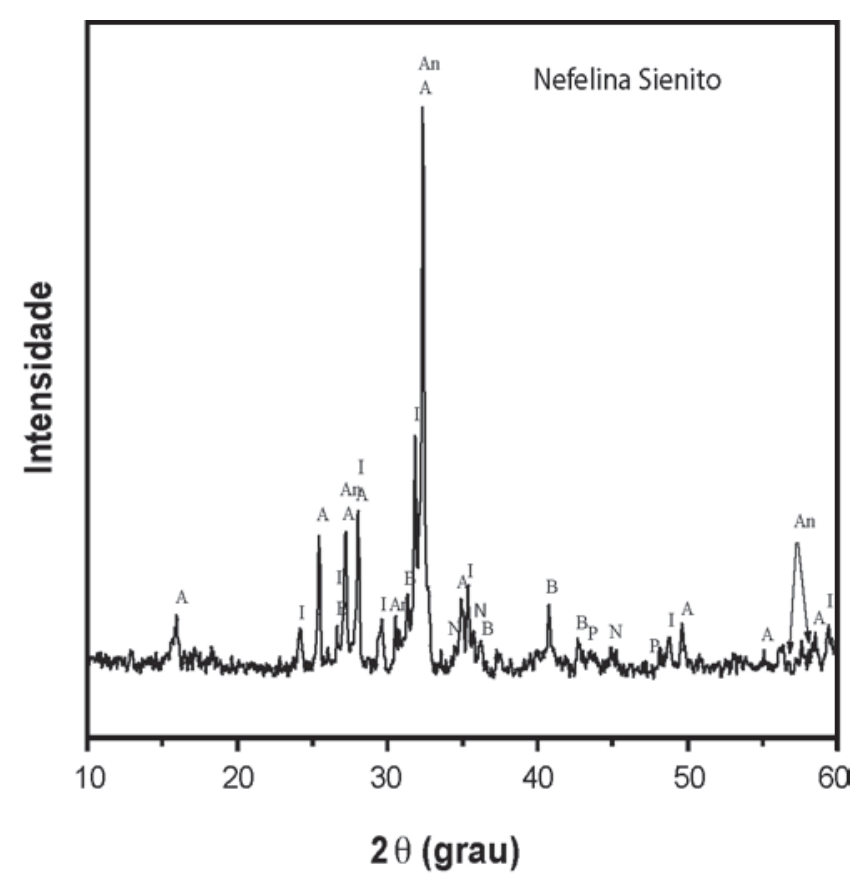

Figura 2: Difratograma de raios $\mathrm{X}$ da Nefelina Sienito de Nova Iguaçu, RJ. A: albita, N: anortita B: biotita, P: pirita, I: microclina.

[Figure 2: X-ray diffraction pattern of the nepheline-syenite. albite $=A ;$ anortite $=N$; biotite $=B$; pyrite $=P$; microcline $=I$.

de difração predominantes de feldspatos, tanto do tipo sódico quanto albítico, e potássico, como a microclina. São observados ainda picos de difração de pequena intensidade da anortita, feldspato cálcico, biotita e pirita. A Fig. 3 mostra o difratograma de raios $\mathrm{X}$ do talco. Nota-se apenas picos característicos do mineral talco.

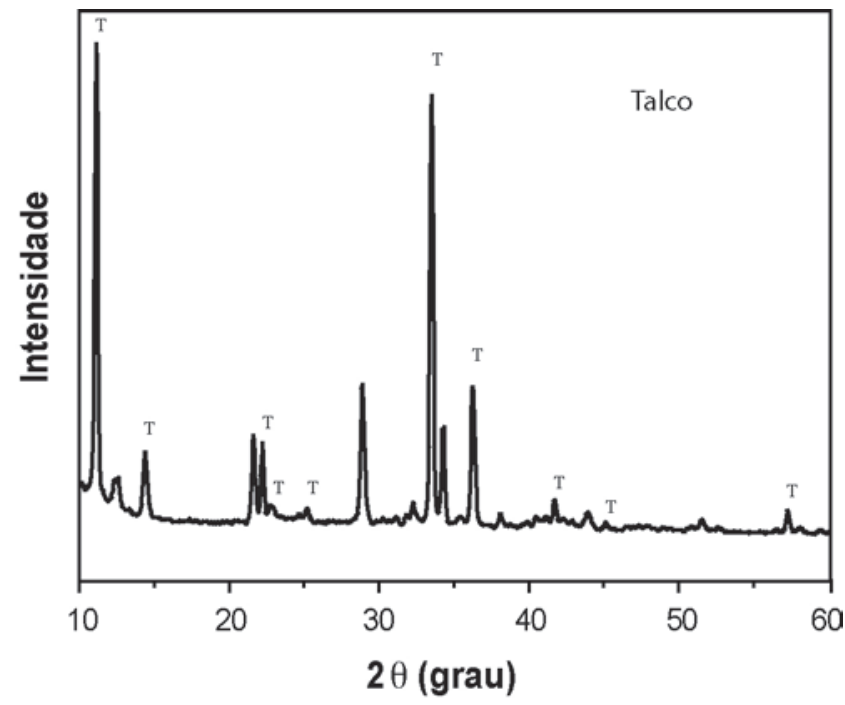

Figura 3: Difratrograma de raios X dpo Talcop (T). [Figure 3: X-ray diffraction pattern of the talc $(T)$ ]

A composição mineralógica semi-quantitativa da nefelina sienito é de aproximadamente $90 \%$ em peso de feldspatos alcalinos [7]. Os demais constituintes são dolomita, pirita, nefelina/sodalita, monazita, biotita e limonita. Já a argila possui aproximadamente $65 \%$ em peso de caulinita, $20 \%$ de quartzo, 9\% de mica e 6\% de hidróxidos [15].

A Tabela II mostra a composição química das matériasprimas utilizadas. A argila é predominantemente constituída de $\mathrm{SiO}_{2}$ e $\mathrm{Al}_{2} \mathrm{O}_{3}$ e possui baixo teor de óxidos alcalinos $\left(\mathrm{K}_{2} \mathrm{O}\right.$ e $\mathrm{Na}_{2} \mathrm{O}$ ). Os óxidos alcalinos são fundentes muito ativos e tem como finalidade à formação de fase líquida, necessária a uma densificação acentuada da cerâmica, após a queima, com consolidação das partículas. Nota-se na nefelina sienito uma quantidade apreciável destes óxidos, tornando-a uma possível matéria-prima para ser utilizada como insumo na fabricação de revestimentos cerâmicos. O talco apresenta

Tabela II - Composição química das matérias-primas. [Table II - Chemical composition of the raw materials.]

\begin{tabular}{cccc}
\hline \multirow{2}{*}{ Constituintes } & \multicolumn{3}{c}{ Matérias-primas (\% em peso) } \\
\cline { 2 - 4 } & Argila & Nefelina Sienito & Talco \\
\hline $\mathrm{SiO}_{2}$ & 48,84 & 58,55 & 62,40 \\
$\mathrm{Al}_{2} \mathrm{O}_{3}$ & 25,94 & 23,50 & \\
$\mathrm{TiO}_{2}$ & 1,30 & - & 3,5 \\
$\mathrm{Fe}_{2} \mathrm{O}_{3}$ & 9,14 & 3,45 & 0,10 \\
$\mathrm{~K}_{2} \mathrm{O}$ & 1,91 & 5,64 & 0,05 \\
$\mathrm{Na}_{2} \mathrm{O}$ & 0,46 & 6,97 & 0,5 \\
$\mathrm{CaO}$ & 0,30 & 2,65 & 0,3 \\
$\mathrm{MgO}$ & 0,83 & 0,74 & 29,25 \\
$\mathrm{SO}$ & - & 1,43 & - \\
Perda ao Fogo & 12,06 & - & 4,90 \\
\hline
\end{tabular}


elevado teor de $\mathrm{SiO}_{2}$ e $\mathrm{MgO}$, que vão contribuir para formar importantes reações durante a etapa de queima.

As Figs. 4 a 6 apresentam as curvas dilatométricas das composições A, A5N e A50NT, respectivamente.

A curva dilatométrica da argila pura A, Fig. 4, mostrou um início de retração a $529{ }^{\circ} \mathrm{C}$ como conseqüência das reações de sinterização dos argilominerais [19]. A elevada perda de massa da argila, atribuída sobretudo à perda de água de constituição da caulinita, contribui significativamente para o incremento da retração. A partir de $1130{ }^{\circ} \mathrm{C}$ a retração da argila tornou-se mais acentuada, o que está comprovando que nesta temperatura as reações de sinterização são bastante pronunciadas. A argila pura apresenta retração até $1378{ }^{\circ} \mathrm{C}$ evidenciando seu comportamento refratário.

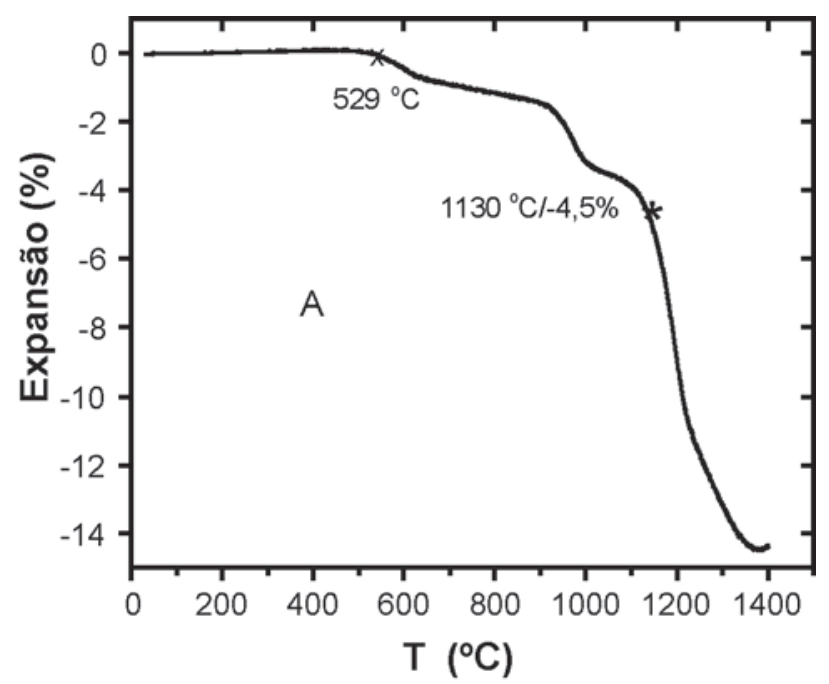

Figura 4: Curva dilatométrica da formulação $\mathbf{A}$.

[Figure 4: Dilatometic curve of the formulation A] .

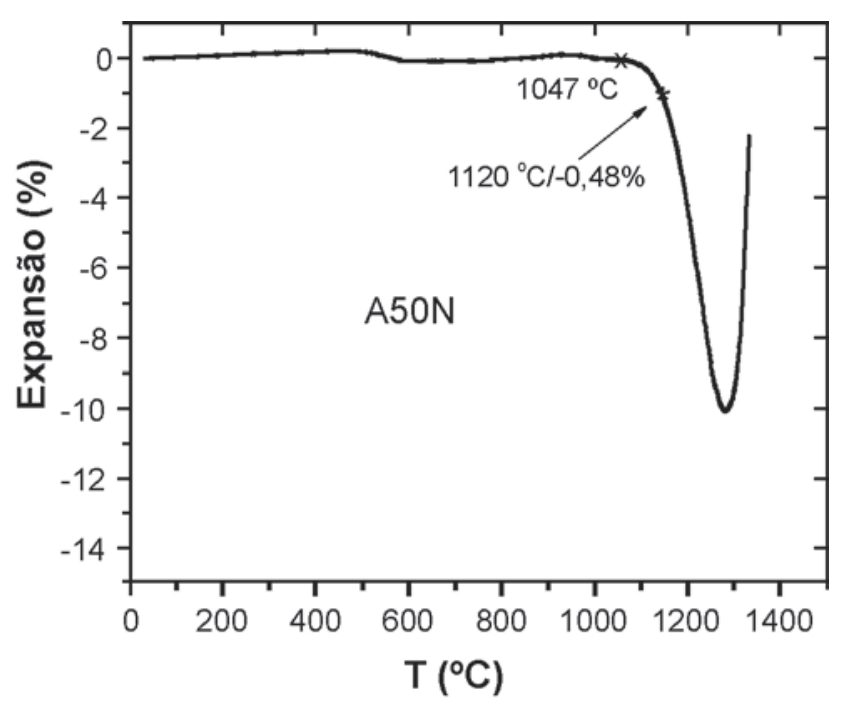

Figura 5: Curva dilatométrica da formulação A50N.

[Figure 5: Dilatometic curve of the formulation A50N].

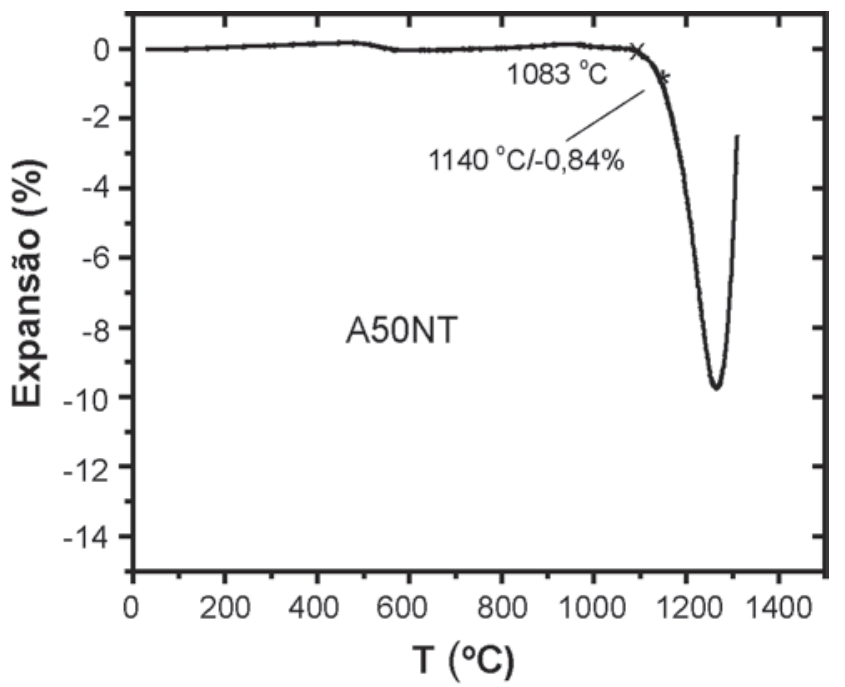

Figura 6: Curva dilatométrica da formulação A50NT. [Figure 6: Dilatometic curve of the formulation A50NT].

Já a curva dilatométrica da argila com nefelina, formulação A50N, Fig. 5, apresentou início de retração a $1047^{\circ} \mathrm{C}$ a partir de $1120{ }^{\circ} \mathrm{C}$. A retração tornou-se então mais acentuada, indicando uma apreciável formação de fase líquida. Já adição de talco, formulação A50NT, Fig. 6, não alterou significativamente o comportamento dilatométrico da formulação A50N. Embora a adição de talco tenha contribuído para reduzir a porosidade da cerâmica, conforme será discutido mais adiante, este efeito não alterou a retração devido à formação de fase cristalina com baixo coeficiente de dilatação térmica.

É possível observar também que na temperatura final de $1175^{\circ} \mathrm{C}$ a argila pura, formulação A, retraiu cerca de 7,5\%. Já com a adição de nefelina sienito, formuação $\mathbf{A 5 0 N}$, a retração foi $5 \%$. Durante o aquecimento até $1130{ }^{\circ} \mathrm{C}$ a argila pura retraiu 4,5\%, enquanto a formulação $\mathbf{A 5 0 N}$ retraiu somente 0,6\%. Estes dados evidenciam dois aspectos importantes: o primeiro é que a argila apresenta uma significativa retração em baixas temperaturas; o segundo é que em temperaturas mais elevadas a adição de nefelina sienito incrementa a retração da argila, sem entretanto aumentar a retração total, pois a elevada retração da argila em baixas temperaturas compensa esta diferença.

A densidade aparente a seco e a densidade aparente de queima das cerâmicas são apresentadas na Fig. 7. A utilização de nefelina sienito possibilitou uma melhora na densificação da argila. Isto é atribuído à granulometria mais grosseira da nefelina sienito em comparação com a argila, possibilitando um melhor empacotamento das partículas durante a etapa de conformação. Observa-se também um aumento da densidade após a etapa de queima para todas as cerâmicas. Isto é devido aos processos de sinterização como difusão no estado sólido e formação de fase líquida, que tende a preencher os poros e assim tornar a cerâmica com densidade superior à densidade a seco. Observa-se também que a adição de talco possibilitou um aumento ainda mais 
significativo da densidade de queima das cerâmicas. Isto comprova que o talco contribui para uma maior formação de fase líquida, atuando como um modificador de fundência na massa cerâmica por meio da formação de eutéticos com os feldspatos.

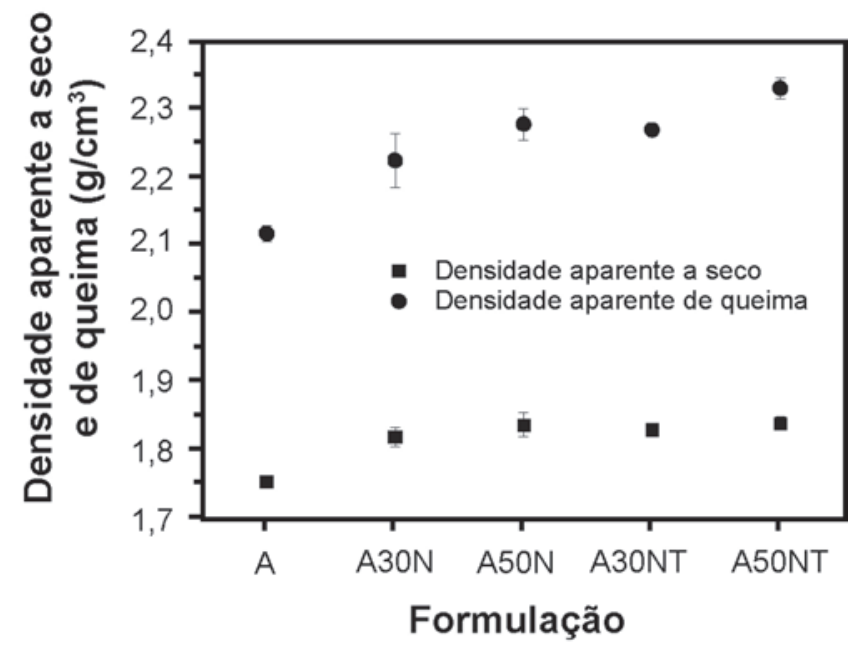

Figura 7: Densidade aparente a seco e de queima das cerâmicas. [Figure 7: Dried and fired bulk density of the ceramics.]

A Fig. 8 apresenta a absorção de água das cerâmicas queimadas a $1175^{\circ} \mathrm{C}$. A argila pura, A, apresenta valores muito superiores de absorção de água em relação às massas contendo nefelina sienito, embora o valor de aproximadamente $7 \%$ de absorção de água seja ainda compatível com revestimento cerâmico do tipo semiporoso [20]. O aumento da quantidade de nefelina sienito incorporado na argila de 30\%, A30N, para 50\%, A50N, não alterou de forma significativa a absorção de água e possibilitou que fosse alcançado o patamar referente ao revestimento tipo grês. Já a incorporação de talco causou uma redução ainda mais significativa da absorção de

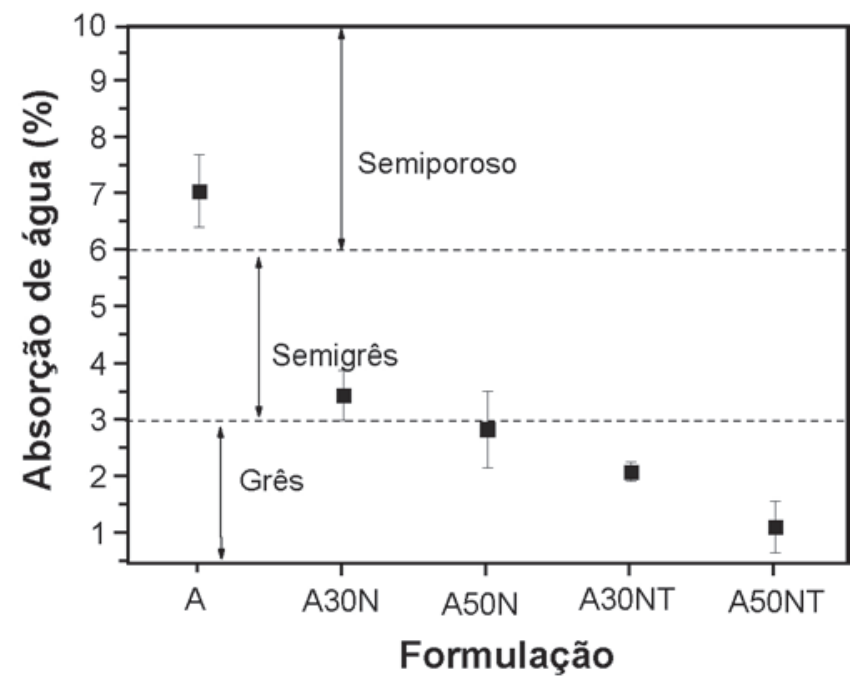

Figura 8: Absorção de água das cerâmicas queimadas a $1175^{\circ} \mathrm{C}$. [Figure 8: Water absorption of the ceramics fired at $1175^{\circ} \mathrm{C}$.] água. A composição com 3,5\% de talco e 30\% de nefelina, A30NT, possibilitou a obtenção de um nível de absorção de água menor que a composição com $50 \%$ de nefelina. Com o incremento de nefelina sienito e talco, formulação A50NT, a absorção de água foi ainda menor, 1,14\%.

A retração linear das cerâmicas pode ser vista na Fig. 9. A retração linear não variou apreciavelmente com o incremento de nefelina sienito e talco, embora a barra estatística de erro seja relativamente elevada para algumas formulações. A princípio este resultado seria contraditório, pois a nefelina sienito e o talco contribuem para acentuar os processos de sinterização, o que poderia aumentar a retração linear das cerâmicas. A explicação para isto é que as formulações com estas matérias-primas apresentaram valores de densidade a seco superiores à argila pura, o que contribui para a redução da retração linear. Além disso, a perda de massa destas formulações também é menor em relação à argila pura.

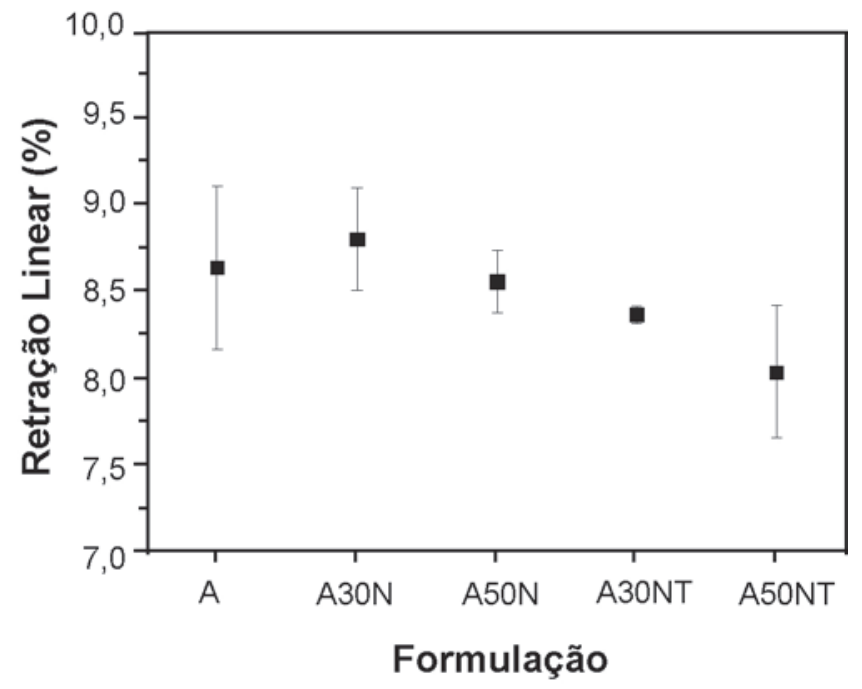

Figura 9: Retração linear das cerâmicas queimadas a $1175^{\circ} \mathrm{C}$. [Figure 9: Linear shrinkage of the ceramics fired at $1175^{\circ} \mathrm{C}$.]

Na Fig. 10 observa-se um aumento significativo da tensão de ruptura à flexão com a utilização de nefelina sienito em comparação com a argila pura. Nota-se também que a utilização de talco nas formulações possibilitou um pequeno incremento da tensão de ruptura à flexão da cerâmica. Isto ocorre, sobretudo, devido ao aumento da porcentagem de fase líquida que contribui para o preenchimento dos poros. Embora a argila pura apresente valor de resistência mecânica compatível com revestimento do tipo semi-grés [19], as demais formulações possibilitam a obtenção de porcelanato. Deve-se ressaltar que os valores de resistência mecânica das formulações foram obtidos com corpos-de-prova de tamanho reduzido. Isso não garante que peças industriais feitas a partir das composições estudadas alcancem o mesmo nível de resistência mecânica obtido nesse trabalho.

A seguir serão mostradas algumas características microestruturais das cerâmicas queimadas a $1175{ }^{\circ} \mathrm{C}$, tais como fases cristalinas de queima e micrografias da região de 


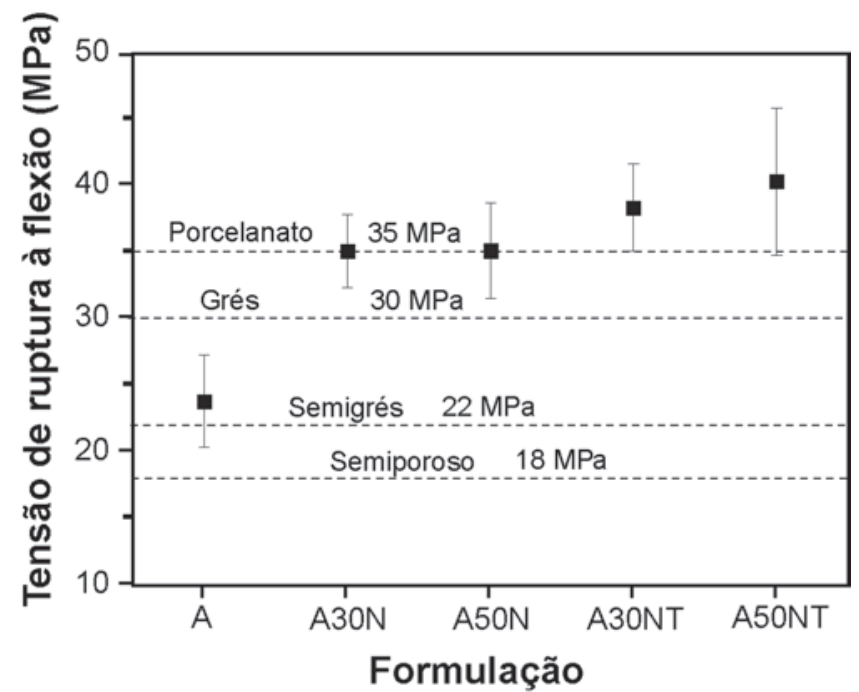

Figura 10: Tensão de ruptura a flexão das cerâmicas queimadas a $1175^{\circ} \mathrm{C}$.

[Figure 10: Flexural rupture strength of the ceramics fired at $1175^{\circ} \mathrm{C}$.]

fratura com mapeamento por EDS. Os resultados mostram que as cerâmicas apresentam importantes transformações durante o processo de queima, com a formação de novas fases. A presença de poros e defeitos é também uma característica marcante na microestrutura das cerâmicas. Estes fatores contribuem fortemente para o comportamento físico e mecânico obtido relativamente às cerâmicas queimadas.

A Fig. 11 apresenta o difratograma de raios $\mathrm{X}$ das cerâmicas queimadas a $1175^{\circ} \mathrm{C}$. Na argila pura, $\mathbf{A}$, nota-se a presença de mulita $(\mathrm{M})$, quartzo (Q) e hematita $(\mathrm{H})$. O quartzo é uma fase residual proveniente da argila. Sua presença na cerâmica é devida à sua inércia e à sua refratariedade durante a queima. Já a hematita e a mulita são fases que aparecem em consequiência da queima. A hematita é proveniente da decomposição de hidróxidos de ferro, enquanto a mulita é proveniente da recristalização da metacaulinita. Pode se observar ainda na Fig. 11 que algumas fases presentes na cerâmica contendo nefelina sienito e argila, A50N, são a mulita, a hematita e o quartzo, a leucita e os feldspatos potássico (microclina), sódico ( albita) e cálcico (anortita). Os feldspatos são as fases mineralógicas predominantes na nefelina sienito. Já a leucita é proveniente da fusão incongruente do feldspato potássico. De acordo com a literatura [10], as temperaturas de fusão da albita, microclina e anortita são de 1120,1180 e $1553{ }^{\circ} \mathrm{C}$, respectivamente. A presença da microclina indica que o feldspato potássico não de fundiu totalmente, evidenciando que com o aumento da temperatura, a porosidade poderia ser ainda mais reduzida. Por outro lado, isto pode acarretar deformações nas cerâmicas. Já a incorporação de talco na formulação com argila e nefelina sienito, A50NT, reduziu a intensidade dos picos de difração da mulita, e possibilitou o aparecimento da cordierita, que reduz o coeficiente de dilatação térmica da cerâmica. É possível observar também que os difratogramas evidenciam que ocorreu formação de fase vítrea, sobretudo,
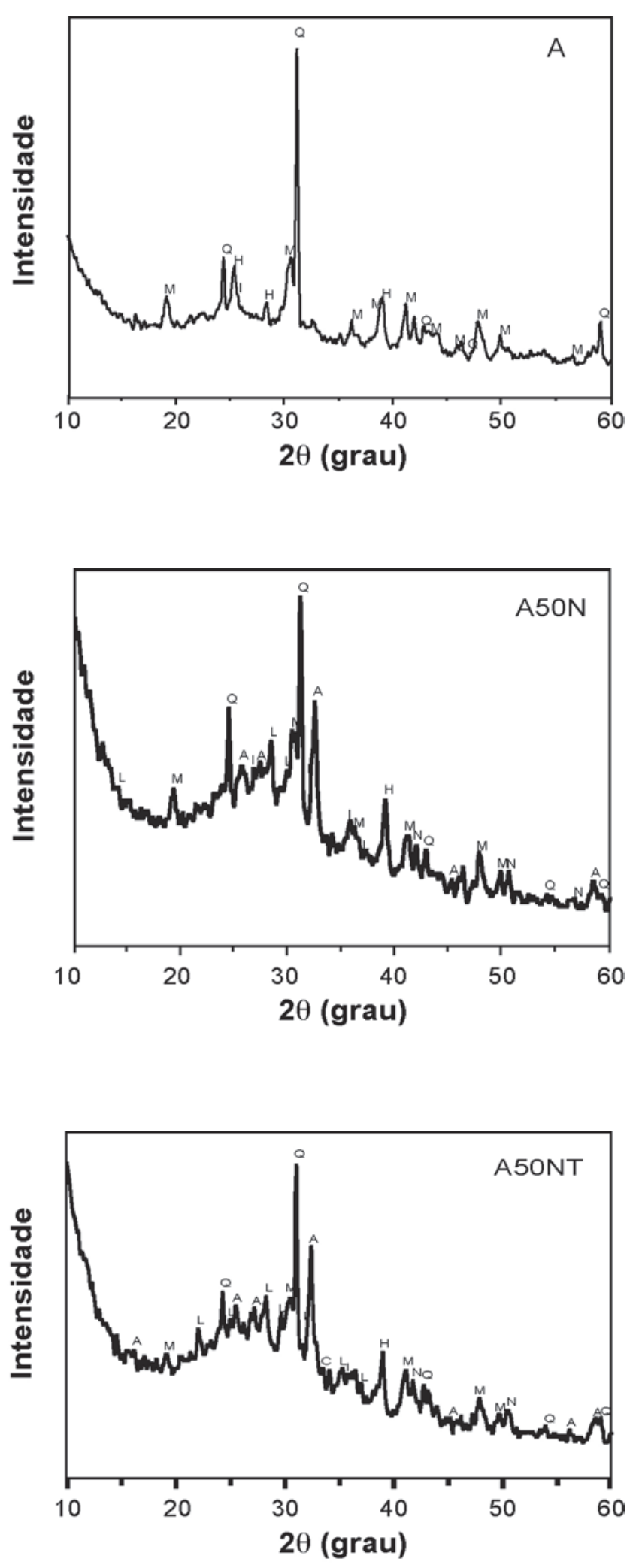

Figura 11: Difratogramas de raios $\mathrm{X}$ das cerâmicas queimadas a $1175{ }^{\circ} \mathrm{C}$. I: Microclina. M: Mulita, Q: Quartzo, L: Leucita, A: Albita, H: Hematita, N: Anortita, C: Cordierita.

[Figure 11: XRD patterns of the ceramics fired at $1175{ }^{\circ} \mathrm{C}$. Microcline = I; Mullite = M; Quartz = Q; Leucite = L; Albite = $\mathbf{A} ;$ Hematite $=\boldsymbol{H} ;$ Anortite $=\mathbf{N} ;$ Cordierite $=\mathbf{C}$. $]$ 
nas formulações com nefelina sienito e talco, devido à elevação do background nestes difratogramas.

A Fig. 12 mostra a superfície de fratura da cerâmica $\mathbf{A}$, de argila pura, queimada a $1175{ }^{\circ} \mathrm{C}$. Embora a textura da cerâmica se apresente relativamente lisa, é observada uma região de defeito associada ao processo de sinterização não totalmente consolidado, além de poros isolados, conforme mostram as setas. Esta característica microestrutural da cerâmica está relacionada às características da argila caulinítica tais como o baixo teor de fundentes, o elevado teor de alumina e a elevada perda de massa durante a queima.
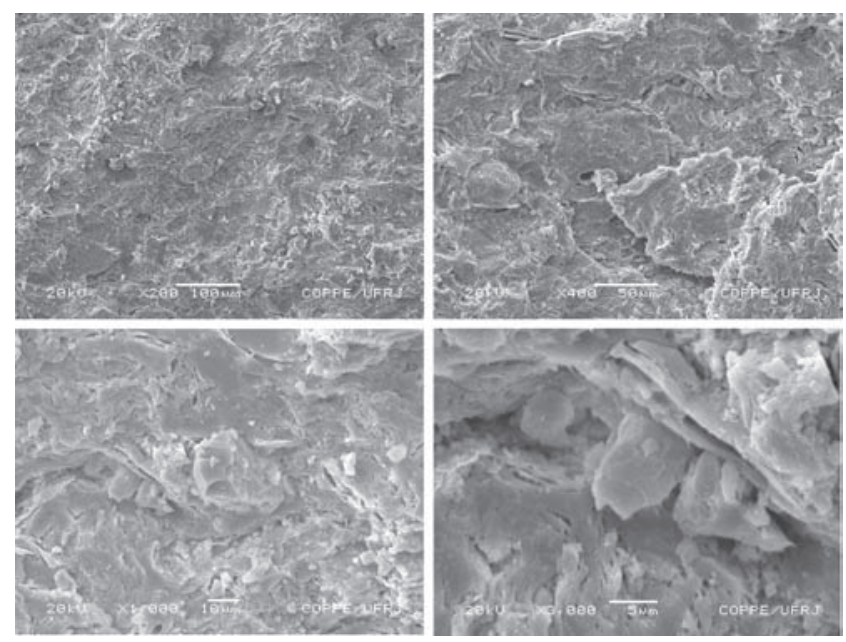

Figura 12: Micrografias obtidas por MEV da superfície de fratura da cerâmica A queimada a $1175^{\circ} \mathrm{C}$.

[Figure 12: SEM micrographs of the fractured surface of the ceramic A fired at $1175^{\circ} \mathrm{C}$.]

Observa-se na Fig. 13 a presença marcante de Si e Al no mapeamento por EDS da cerâmica A. Estes elementos estão predominantemente combinados formando a matriz vítrea e as fases de aluminosilicatos como a mulita. É possível observar também regiões com elevadas concentrações isoladas de $\mathrm{Si}$, de $\mathrm{Al}$ e de $\mathrm{Fe}$. No caso do Si, estas concentrações estão associadas a partículas de sílica livre na forma de quartzo. Já o $\mathrm{Al}$ e o Fe podem estar associados a partículas de alumina- $\alpha$ [21] e de hematita, respectivamente.

A Fig. 14 mostra a superfície de fratura da cerâmica A50N queimada a $1175{ }^{\circ} \mathrm{C}$. As micrografias obtidas permitem visualizar uma microestrutura com textura ainda mais fina e com porosidade inferior em relação à cerâmica $\mathbf{A}$, embora ainda existam regiões com defeitos, de acordo com as setas. A nefelina sienito utilizada na formulação da cerâmica A50N atuou como fundente propiciando, na etapa de queima, maior formação de fase líquida e consequentemente a obtenção de uma cerâmica com porosidade reduzida. Esta característica microestrutural da composição A50N justifica o aumento de 47,2\% da tensão de ruptura à flexão em comparação com a massa A, e uma redução de 59,5\% da absorção de água.

A Fig. 15 mostra a micrografia da superfície de fratura da cerâmica A50N queimada a $1175^{\circ} \mathrm{C}$ com análise química e mapeamento por EDS. Pode ser observado um maior teor de K em relação à argila pura da Fig. 13. Nota-se também uma partícula de quartzo, identificado na micrografia devido à alta concentração de silício naquela região, dispersa na matriz vítrea. Ao redor desta partícula de quartzo é possível observar trincas, possivelmente associadas à diferença nos coeficientes de dilatação térmica do quartzo e da matriz vítrea.
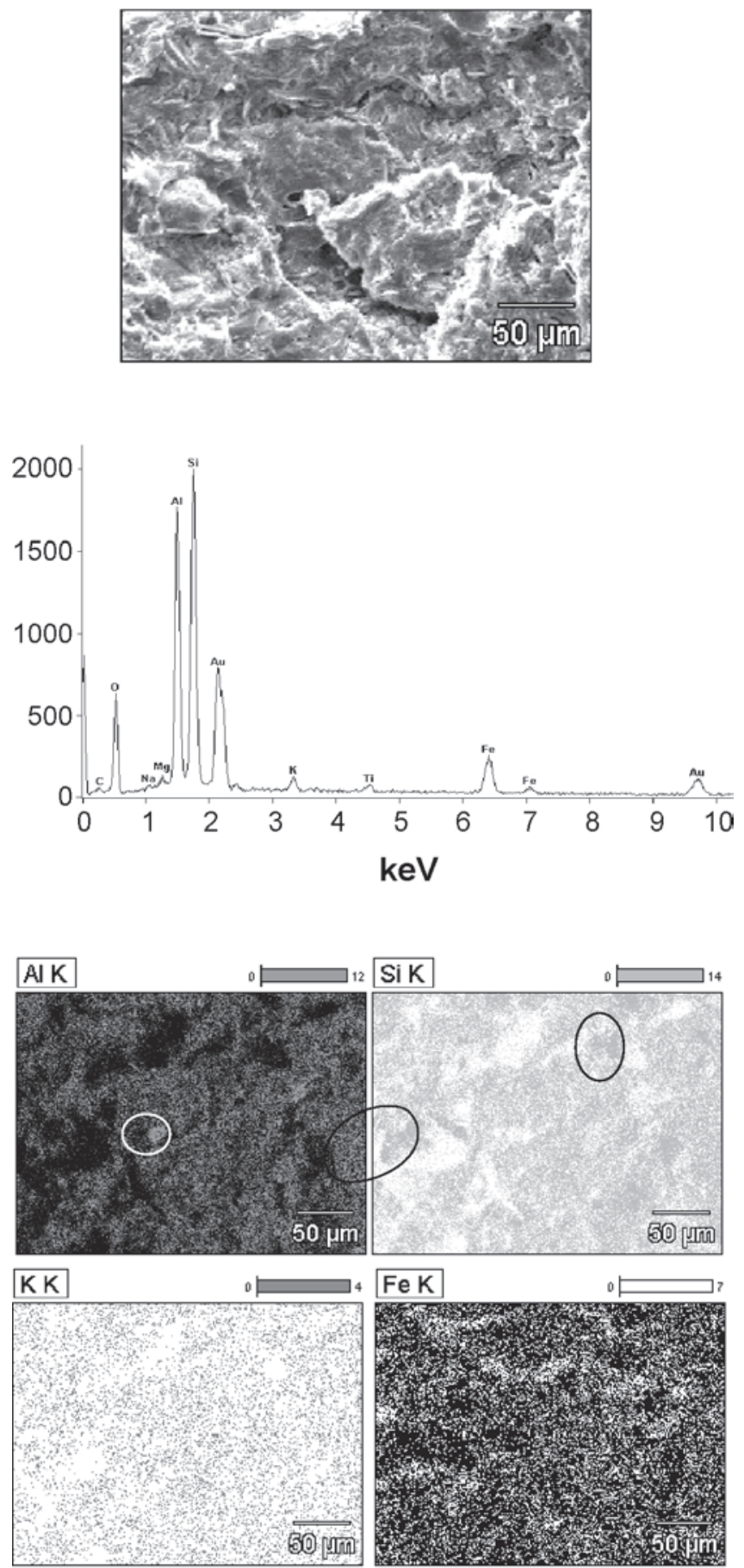

Figura 13: Micrografias obtidas por MEV da superfície de fratura da cerâmica A queimada a $1175^{\circ} \mathrm{C}$ com mapeamento por EDS. [Figure 13: SEM micrographs of the fractured surface of the ceramic A fired at $1175^{\circ} \mathrm{C}$ with EDS mapping.] 

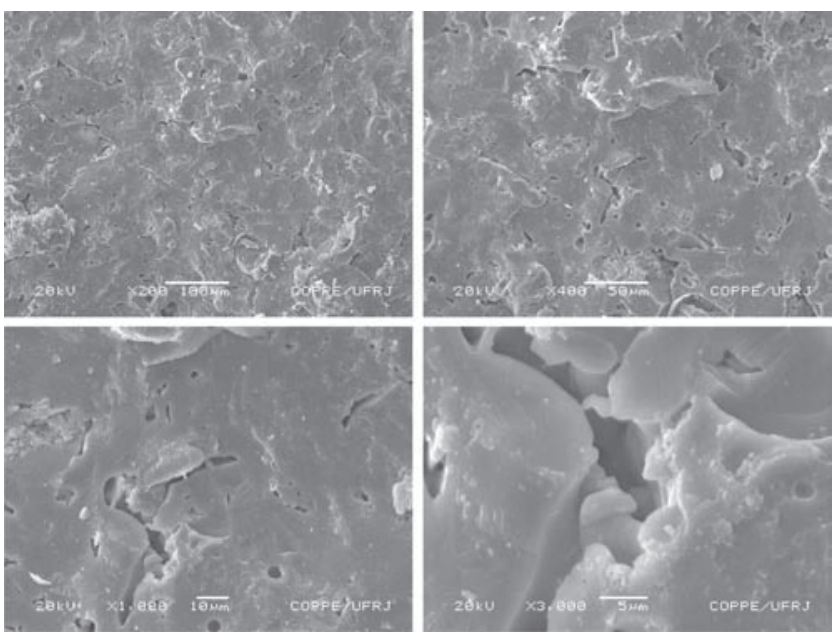

Figura 14: Micrografias obtidas por MEV da superfície de fratura da cerâmica A50N queimada a $1175{ }^{\circ} \mathrm{C}$.

[Figure 14: SEM micrographs of the fractured surface of the ceramic A50N fired at $1175{ }^{\circ} \mathrm{C}$.]
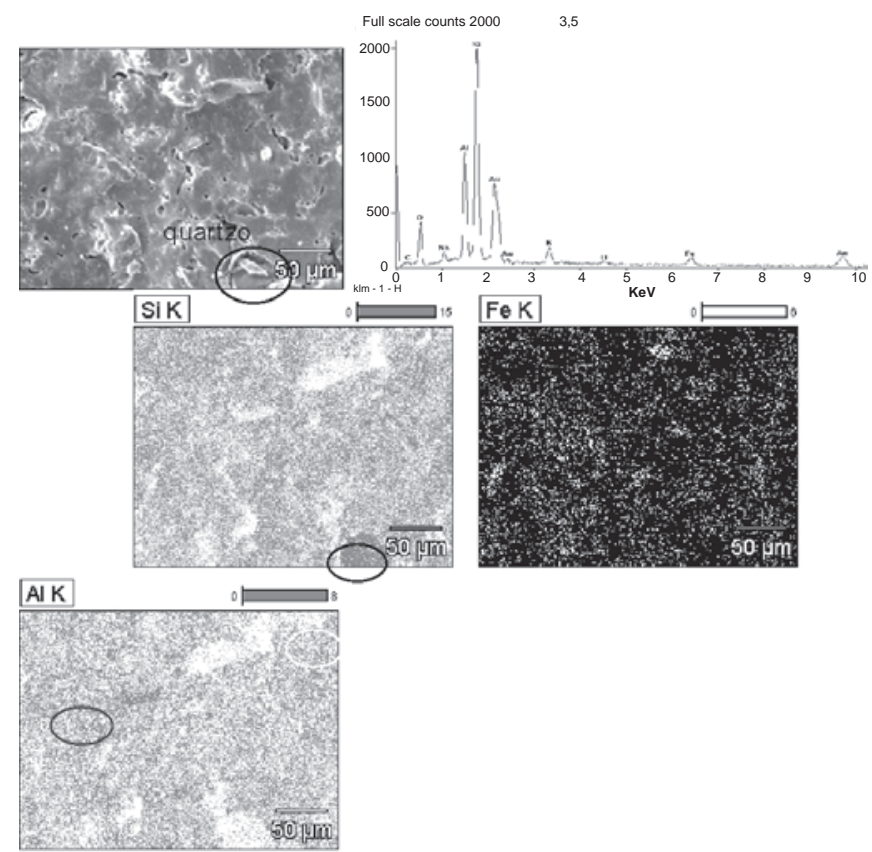

Figura 15: Micrografias obtidas por MEV da superfície de fratura da cerâmica A50N queimada a $1175^{\circ} \mathrm{C}$ com mapeamento por EDS.

[Figure 15: SEM micrographs of the fractured surface of the ceramic A50N fired at $1175^{\circ} \mathrm{C}$ with EDS mapping.]

A Fig. 16 mostra a superfície de fratura da cerâmica A50NT queimada a $1175{ }^{\circ} \mathrm{C}$. A microestrutura desta cerâmica também possui uma textura fina e com baixa porosidade. São observados poros esféricos a arredondados, típicos de estágio final de sinterização. O talco propiciou maior formação de fase vítrea em relação à cerâmica A50N. A adição de talco na presença de nefelina sienito facilitou também maior formação de fase liquida em relação à cerâmica A50N, levando à cerâmica a desenvolver maior densificação. Pelas micrografias obtidas não se percebe uma diferença apreciável entre estas últimas formulações. Esta diferença pode ser vista na análise das propriedades físicas e mecânicas, Figs. 7 a 10, apresentadas anteriormente. A adição de talco possibilitou um incremento de 14,8\% na resistência mecânica da cerâmica e uma redução de 34,8\% na absorção de água, em relação à composição A50N.
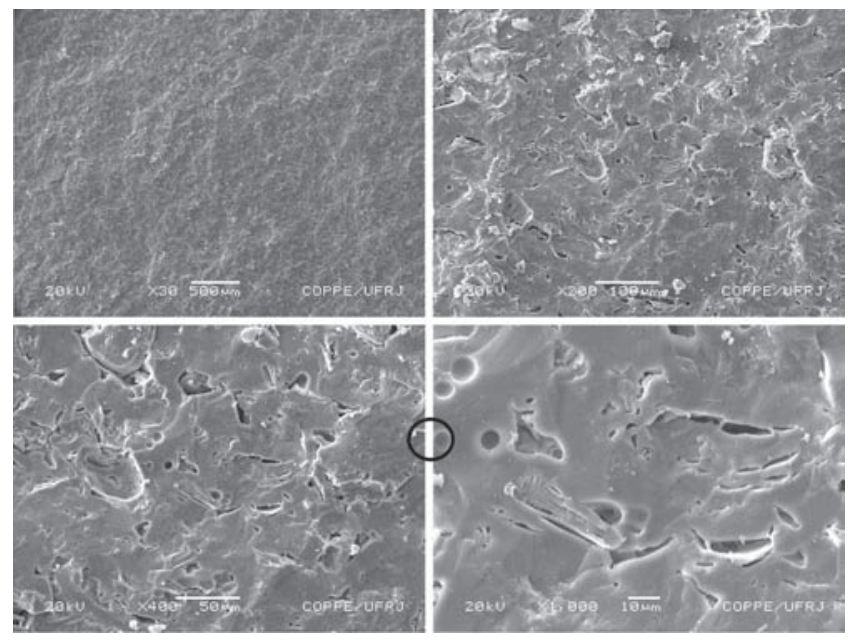

Figura 16: Micrografias obtidas por MEV da superfície de fratura da cerâmica A50NT queimada a $1175^{\circ} \mathrm{C}$.

[Figure 16: SEM micrographs of the fractured surface of the ceramic A50NT fired at $1175^{\circ} \mathrm{C}$.]

A Fig. 17 mostra a micrografia da superfície de fratura da cerâmica A50NT queimada a $1175{ }^{\circ} \mathrm{C}$ com análise química e mapeamento por EDS. Nota-se em algumas regiões desta micrografia maior quantidade do elemento Mg devido a sua considerável concentração no talco. O Mg
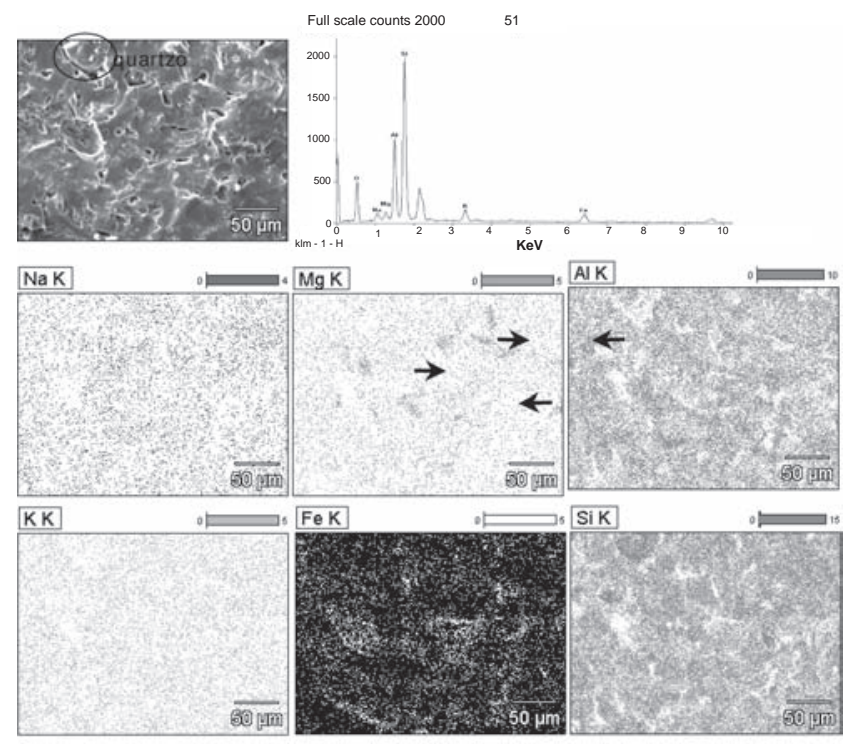

Figura 17: Micrografias obtidas por MEV da superfície de fratura da cerâmica A50NT queimada a $1175{ }^{\circ} \mathrm{C}$ com espectro e mapeamento por EDS.

[Figure 17: SEM micrographs of the fractured surface of the ceramic A50NT fired at $1175^{\circ} \mathrm{C}$ with EDS mapping.] 
está combinado com o $\mathrm{Si}, \mathrm{Al}$ e $\mathrm{O}$, formando a fase cristalina cordierita. Pode-se notar também uma partícula de quartzo com trincas ao seu redor.

Como considerações finais, pode-se afirmar que os resultados preliminares deste trabalho são bastante favoráveis a uma formulação de revestimento para pavimento utilizando uma argila caulinítica, incorporada com nefelina sienito e talco. Na continuidade deste trabalho, pretende-se direcioná-lo na tentativa de melhorar as propriedades físicas e mecânicas das cerâmicas aumentando a densidade a seco, otimizando a relação talco/nefelina sienito, avaliando o coeficiente de dilatação térmica das cerâmicas e verificando ainda o intervalo de queima mais apropriado.

\section{CONCLUSÕES}

A nefelina sienito possibilitou uma melhoria significativa nas propriedades de queima da argila caulinítica permitindo alcançar as especificações de revestimento cerâmico do tipo semi-grês. A utilização de talco melhorou ainda mais as propriedades de queima da cerâmica no sentido de garantir a obtenção de revestimento cerâmico do tipo grês. A microestrutura das cerâmicas formuladas com argila caulinítica e nefelina sienito queimadas a $1175{ }^{\circ} \mathrm{C}$ apresenta poros isolados e fases cristalinas como quartzo, leucita, mulita, hematita e feldspatos dispersos numa matriz vítrea. A adição de talco diminuiu a quantidade de mulita e possibilitou o aparecimento da cordierita. A melhor formulação da cerâmica com base em argila caulinítica foi obtida com adição de 50\% de nefelina sienito e 3,5\% de talco, o que possibilitou alcançar, a $1175^{\circ} \mathrm{C}$, uma tensão de ruptura à flexão de $40,4 \mathrm{MPa}$ e uma absorção de água de $1,1 \%$, correspondentes a revestimentos do tipo grés.

\section{AGRADECIMENTOS}

Ao CNPq (Proc. 400915/2004-9), à FAPERJ e à FENORTE/TECNORTE. Nossos agradecimentos também ao Laboratório de Microscopia Eletrônica da PEMM/COPPE/ UFRJ, que permitiu a utilização de seu equipamento.

\section{REFERÊNCIAS}

[1] I. S. Ramos, M. G. Alves, J. Alexandre, Ceram. Ind. 11, 1 (2006) 28.
[2] J. E. E. Navarro, J. L. A. Albaro, Técnica Cerâmica 91 (1981) 119.

[3] C. M. F. Vieira; L. P. Fonseca Jr., S. N. Monteiro, Cerâmica 52, (2006) 138.

[4] C. M. F. Vieira, S. N. Monteiro, J. Duailibi F., Cerâmica Industrial 6, 6 (2001) 43.

[5] C. M. F. Vieira, E. T. A. Souza, S. N. Monteiro, Cerâmica 50, 314 (2004) 122.

[6] P. M. Andrade, H. S. Nogueira Neto, S. N. Monteiro, C. M. F. Vieira, Cerâmica 51, 320 (2005) 362.

[7] S. C. A França, J.A. Sampaio, Anais do XIX ENTMME, Recife, PE (2002) 2.

[8] E. D. Lynch, A. W. Allen, J. Am. Ceram. Soc. 33, 4 (1950) 117.

[9] S. Sabedot, A. R. Volkmann, C. H. Sampaio, Anais do $60^{\circ}$ Cong. Anual da ABM, Belo Horizonte, MG (2005).

[10] G. P. Emiliani, F. Corbara, Tecnología Cerámica - Le Materia Prime, Gruppo Editoriale Faenza Editrice, Faenza, Itália (1999) 98.

[11] A. Barba, V. Beltrán, C. Felíu, J. Garcia, F. Ginés, E. Sánchez, V. Sanz, Materias Primas para la Fabricación de Soportes de Baldosas Cerámicas, Instituto de Tecnologia Cerámica-AICE, Castellón, Espanha (2002) 181.

[12] P. Grosjean, Int. Ceram. 35, 5 (1986) 23.

[13] D. M. Ibrahim, E. H. Sallam, A. A. Khalil, S. M. Naga, Ceram. Ind. 7, 2 (1981) 69.

[14] D. Lepkova, L. Povlova, Interceram. 47, 6 (1998) 369.

[15] S. N. Monteiro,C. M. F. Vieira, Tile \& Brick Int. 18, 3 (2002) 152.

[16] G. Biffi, Porcelain Stoneware - Production Manual and Methods of Use, Faenza, Gruppo Editoriale Faenza Editrice, Faenza, Itália (1999) 127.

[17] American Society for Testing and Materials - ASTM, Water Absorption, Bulk Density, Apparent Porosity, and Apparent Specific Gravity of Fired Whiteware Products, C 373-72 (1972).

[18] American Society for Testing and Materials - ASTM, Flexural Properties of Ceramic Whiteware Materials, C 67477 (1977).

[19] S. N. Monteiro, C. M. F. Vieira, Ceram. Int. 30 (2004) 381.

[20] Associação Brasileira de Normas Técnicas - ABNT, Placas Cerâmicas para Revestimento - especificação e métodos de ensaio, NBR-13818, Rio de Janeiro (1997) 78p. [21] K. Weffers, G. M. Bell, Technical Paper n. 19, Alcoa Research Laboratories, Pittsburgh (1972).

(Rec. 27/03/2007, Rev. 27/11/2007, Ac. 14/12/2007) 